University of Montana

ScholarWorks at University of Montana

$5-2006$

\title{
A Framework for Understanding Ecological Traps and an Evaluation of Existing Evidence
}

Bruce A. Robertson

Richard L. Hutto

university of montana, hutto@mso.umt.edu

Follow this and additional works at: https://scholarworks.umt.edu/biosci_pubs

Part of the Biology Commons

Let us know how access to this document benefits you.

\section{Recommended Citation}

Robertson, Bruce A. and Hutto, Richard L., "A Framework for Understanding Ecological Traps and an Evaluation of Existing Evidence" (2006). Biological Sciences Faculty Publications. 284.

https://scholarworks.umt.edu/biosci_pubs/284

This Article is brought to you for free and open access by the Biological Sciences at ScholarWorks at University of Montana. It has been accepted for inclusion in Biological Sciences Faculty Publications by an authorized administrator of ScholarWorks at University of Montana. For more information, please contact

scholarworks@mso.umt.edu. 


\title{
A FRAMEWORK FOR UNDERSTANDING ECOLOGICAL TRAPS AND AN EVALUATION OF EXISTING EVIDENCE
}

\author{
Bruce A. Robertson ${ }^{1}$ and Richard L. Hutto \\ Division of Biological Sciences, University of Montana, Missoula, Montana 59812 USA
}

\begin{abstract}
When an animal settles preferentially in a habitat within which it does poorly relative to other available habitats, it is said to have been caught in an "ecological trap." Although the theoretical possibility that animals may be so trapped is widely recognized, the absence of a clear mechanistic understanding of what constitutes a trap means that much of the literature cited as support for the idea may be weak, at best. Here, we develop a conceptual model to explain how an ecological trap might work, outline the specific criteria that are necessary for demonstrating the existence of an ecological trap, and provide tools for researchers to use in detecting ecological traps. We then review the existing literature and summarize the state of empirical evidence for the existence of traps. Our conceptual model suggests that there are two basic kinds of ecological traps and three mechanisms by which traps may be created. To this point in time, there are still only a few solid empirical examples of ecological traps in the published literature (although those few examples suggest that both types of traps and all three of the predicted mechanisms do exist in nature). Therefore, ecological traps are either rare in nature, are difficult to detect, or both. An improved library of empirical studies will be essential if we are to develop a more synthetic understanding of the mechanisms that can trigger maladaptive behavior in general and the specific conditions under which ecological traps might occur.
\end{abstract}

Key words: ecological trap; evolutionary trap; habitat preference; maladaptive behavior.

\section{INTRODUCTION}

Animals choose (consciously or not) among options related to all aspects of their lives (e.g., food types, mates, territory locations). Habitat choice is a consequence of natural selection having favored individuals that recognize, are attracted to, and preferentially settle in, the best available habitat (Fretwell and Lucas 1970). Cues of any kind (e.g., tail length, tree density) that are used as the basis of an animal's choice are usually at least one step removed from the ultimate reason that the choice has been favored by natural selection (Tinbergen 1963, Sherman 1988). This is because an animal cannot always know the consequences of a choice at the time a choice needs to be made. In terms of habitat selection behavior, where an animal makes a choice about where to live, that choice may affect the individual's survival and reproductive success at some later point in time but, again, the ultimate factors that determine success may

Manuscript received 22 August 2005; revised 28 September 2005; accepted 8 November 2005. Corresponding Editor: A. Sih.

${ }^{1}$ E-mail: bruce.robertson@mso.umt.edu not be evident at the time the choice has to be made (Hutto 1985).

Because animals must assess the suitability of habitats indirectly, it is possible for the attractiveness of a habitat to become uncoupled from its suitability for survival and reproduction, such that lower quality habitats may be as attractive as, or even more attractive (i.e., more likely to elicit settling and reproduction) than, higher quality habitats. This can happen when animals whose behaviors have been shaped by exposure to one set of conditions are suddenly confronted by novel or very different conditions (Levins 1968). For example, sea turtle hatchlings normally rely on light cues from the open horizon to orient and migrate toward the ocean after emerging from the nest at night. However, light pollution from beachfront structures can cue hatchlings to migrate inland instead, where their survival is unlikely (Witherington 1997).

The most extreme situation, where a poor habitat becomes relatively more attractive, thus "baiting" individuals to settle, has been termed an "ecological trap" (Dwernychuk and Boag 1972, Gates and Gysel 1978). An ecological trap is a scenario that occurs when 
sudden environmental change (e.g., brood parasitism, predation, pesticide use, human disturbance) acts to uncouple the cues that individuals use to assess habitat quality from the true quality of the environment (Dwernychuk and Boag 1972, Gates and Gysel 1978). An animal's preference remains unchanged, but the positive outcome normally associated with a given cue is now a negative outcome (Misenhelter and Rotenberry 2000). The potential for being deceived is precisely why mimicry, brood parasitism, and a host of other behavioral phenomena are possible.

The mechanism that underlies an ecological trap is more broadly applicable. Organisms rely on environmental cues to make a variety of behavioral and lifehistory "decisions," such as when to migrate, when to reproduce, with whom to mate, how many young to bear, and what to eat. Schlaepfer et al. (2002) coin the term "evolutionary trap" to describe this broader set of situations in which use of a formerly reliable behavioral cue has become maladaptive because of a sudden anthropogenic disruption. Note that all evolutionary traps, including ecological traps, involve the behaviors of individual organisms. Thus, in contrast with some definitions of ecological traps (e.g., Battin 2004), we wish to emphasize here that an ecological trap is a behavioral, not a population phenomenon.

Now widely recognized as a theoretical possibility within academic circles, the concept of an ecological trap represents a bridging of the disciplines of evolutionary biology and cognitive ecology. As a potentially new mechanism explaining widespread population declines of native species, the ecological trap concept has also garnered a great deal of attention from conservation interests. Even so, and even though the concept of an ecological trap was first described more than a quartercentury ago (Dwernychuk and Boag 1972), the extent to which ecological traps operate in the world is still unclear. In addition, the current mechanistic framework developed to elucidate the possible processes that might create ecological traps (Schlaepfer et al. 2002) is not sufficient to describe the full range of interactions between cue sets and ultimately important factors that can trigger ecological traps.

The purpose of this paper is to (1) develop a conceptual framework within which the concept of an ecological trap can be better understood, (2) present the criteria needed to demonstrate the existence of an ecological trap, (3) use existing literature to evaluate the empirical evidence for the existence of ecological traps, and (4) discuss the implications of our literature review.

\section{A conceptual model for an ecological trap}

An ecological trap is likely to arise for one of three reasons, which differ slightly from the two avenues described by Schlaepfer et al. (2002). Each results from decoupling the attractiveness of, and the suitability in, the altered habitat. First, an ecological trap will arise if the settlement cues normally used by an individual change in intensity, type, or number such that the habitat becomes more attractive while habitat suitability remains unchanged (the settlement cues have changed, but not the ultimate factors). The second way in which a trap is likely to arise is if the environment of the organism is altered in such a way that, although the original cue set that elicits a settling response is unaltered, the quality of the habitat has decreased (the ultimate factors have changed, but the settling cues have not). Thirdly, alterations to a habitat may alter the settlement cues, causing an increase in the attractiveness of the habitat, while reducing the suitability of the habitat for survival and/or reproduction (both settlement cues and ultimately important factors change). Thus, habitat alteration capable of creating an ecological trap must (1) alter the cue set (increasing its attractiveness), (2) decrease the suitability of a habitat, or (3) do both simultaneously.

To illustrate these alternatives more fully, consider four scenarios. In scenario A, suppose that the density of shrubs is the primary cue an organism uses to assess habitat quality, and that shrub density in an area of sparse shrub cover is artificially increased to normal levels through a restoration planting program. If the perceived value of this habitat (Habitat $\mathrm{X}$ ) is now greater than its actual suitability, and if the cue stimulus value is now similar to that of a second habitat (Habitat Y), which is normally of higher quality, both habitats would appear equally attractive to the animal, and, unable to distinguish a difference in suitability between Habitats $\mathrm{X}$ and $\mathrm{Y}$, the animal would be equally likely to settle in each despite the fact that Habitat $\mathrm{X}$ is of lower quality. This kind of scenario would lead to what we call an "equal-preference trap."

In scenario B, suppose the primary cue (shrub density) is artificially increased in value to a supernormal level (so that it serves, in effect, as a "supernormal releaser"). Habitat X would now appear to be even more attractive than Habitat $Y$, and an animal choosing between Habitat $\mathrm{X}$ and $\mathrm{Y}$ would select Habitat $\mathrm{X}$. Thus, it would prefer (be more likely to settle in) the lowerquality habitat. At a population level, scenario B would probably have more severe demographic consequences than the equal-preference trap represented by scenario A because animals would actually be drawn away from the higher-quality habitat (Habitat Y) as a result of their preference for the lower-quality habitat (Habitat X). This kind of scenario, in which animals actively prefer the lower-quality habitat, would lead to what we call a "severe trap."

In scenario $\mathrm{C}$, suppose a portion of Habitat $\mathrm{X}$ is altered such that the inherent suitability is reduced, while the settlement cues remain unaltered. For example, suppose that an insectivorous bird species chooses to settle on the basis of the appearance of fresh green vegetation. Next, suppose that forest managers spray an area for insects so that two options exist for an 
insectivorous bird - one where insect densities available later in the season are well correlated with the amount of fresh green vegetation (unaltered Habitat X) and another where that correspondence has been severed due to spraying (altered Habitat X). An animal choosing between the two habitats would be equally likely to settle in both, illustrating how a change in the suitability of a patch of highly attractive habitat in the absence of a change in settling cues can result in an equal-preference trap.

Scenario D is similar to scenario $\mathrm{C}$ in that a portion of Habitat $\mathrm{X}$ is reduced in suitability, but in this scenario, there is also a simultaneous increase in the value of a settlement cue. Hypothetically, suppose that the particular chemical spray used by forest managers also makes the vegetation glisten so that it appears to be fresher and greener than normal. Habitat $\mathrm{X}$ is now perceived as having a "very high" attractiveness even though it has a "low" suitability. An animal choosing between unaltered Habitat $\mathrm{X}$ and altered Habitat $\mathrm{X}$ would prefer the altered habitat despite the fact that it is poorer in quality. The simultaneous reduction in suitability and increase in attractiveness results in the creation of a severe trap where animals will be actively drawn away from high-quality habitat by the strong attractiveness of the low-quality habitat.

Two important results emerge from this conceptual model. First, there are two quantitatively different types of ecological traps - severe and equal-preference traps. Second, traps can occur via three mechanisms: (1) an increase in the attractiveness of a habitat in the absence of a change in its suitability, (2) a reduction in habitat suitability without a loss in attractiveness, or (3) a simultaneous increase in the attractiveness and reduction in suitability of a habitat.

Our model also emphasizes the idea that ecological traps result from recent or sudden changes to environments that decouple behavioral cues from habitat quality. This is probably because the most dramatic and interesting examples of ecological traps involve changes that are sudden in evolutionary time. Furthermore, traps triggered by rapid changes that result in strong negative fitness consequences are those most likely to trigger population crashes and so are most pertinent to conservation biologists. On the other hand, there are factors that could contribute to the long-term persistence of ecological traps. For example, if the spatial extent of a trap habitat is very small relative to the extent of other suitable habitats, it will likely exert only a minor selection pressure on the population as a whole. Therefore, recent changes to natural environments are most likely to create ecological traps, but recent change is not necessary.

In summary, the model suggests that in order to demonstrate the existence of an ecological trap, the following lines of evidence are required: (1) individuals should have exhibited a preference for one habitat over another (in a severe trap) or an equal preference for both habitats (in an equal-preference trap); (2) a reasonable surrogate measure of individual fitness should have differed among habitats; and (3) the fitness outcome for individuals settling in the preferred habitat or equally preferred habitat (depending on the kind of trap, as described in the conceptual model above) must have been lower than the fitness attained in other available habitats. In other words, individuals cannot experience the greatest fitness consequences from settling in the preferred habitat. Using a strict application of these three criteria, we examine the empirical evidence for the existence of ecological traps, and we ask which mechanisms are most likely to result in ecological traps.

\section{Methods}

We examined peer-reviewed articles in which there was reported evidence for the existence an ecological trap. A search of the literature was conducted using the Ingenta, BIOSIS, Biological Abstracts, AGRICOLA, and Wildlife and Ecology Studies Worldwide databases from 1969 to 2005. We initially confined our search to the terms "ecological trap," "evolutionary trap," and "maladaptive." The bibliographies of published papers captured in this search were also examined for the identification of other relevant studies. Therefore, many references were initially located because they had been cited as examples of ecological traps by other authors.

We evaluated all references to determine if they met the three criteria necessary to demonstrate the existence of an ecological trap. With respect to the first criterion, it is important to note that the demonstration of habitat preference is not the same thing as the demonstration of nonrandom habitat use or of differences in density among habitats (Van Horne 1983). While relatively high densities of individuals in a habitat may suggest a preference for that habitat, such a pattern may result, for example, when individuals are displaced from preferred habitat by dominant individuals (Sherry and Holmes 1988). There are a multitude of situations in which density of individuals in a habitat might not be positively correlated with a preference for that habitat (summarized in Railsback et al. 2003). As such, we do not consider density to be a reliable surrogate measure of habitat preference. Furthermore, the term "habitat preference" is not a synonym for "habitat use" or "habitat selection." These terms have very different meanings even though they are frequently used interchangeably. We define preference here as "the likelihood of a resource being chosen if offered as an option with other available options" (Johnson 1980). Options must be detectable or it cannot be concluded that the option that is selected is the preferred one. Factors such as competition, predation, and aggression may exert costs upon selection by a particular habitat and, over evolutionary time, should contribute to the shaping of behavioral decision-making algorithms that guide animals to conditions in which those costs are minimized. Because habitat selection is defined as the process of 
choosing a habitat in which to settle, presumably based on innate or learned preferences, preference cannot be demonstrated without observing the process of habitat selection by individuals directly or by observing some necessary consequence of that process.

Based on the formal definition above, preference can be measured most reliably by observing the behavioral decisions of individuals or by inferring preference from patterns in time and space that necessarily result from this behavior. We can envision five possible ways to assess whether an organism actually prefers one habitat over another, and we suggest that multiple lines of evidence would provide the clearest case for the existence of habitat preference.

1. Settlement patterns.-Migratory taxa, such as many insects and birds, make excellent study species to test the ecological trap hypothesis because they colonize breeding habitat anew each year, making it possible to observe the behavioral process of habitat selection and to infer preference from settlement patterns (Krebs 1971). Thus, arrival time should be an accurate index of preference and, assuming that numerous individuals respond similarly to a given set of environmental cues, the average arrival date among males within one habitat type should represent a preference ranking relative to other habitat types (e.g., Székely 1992, Remeš 2003, Sergio and Newton 2003).

2. Distribution of dominant individuals.-In some species, there may be a clear dominance hierarchy. Under conditions in which there is competition for resources within a habitat, preference may also be inferred from the distribution of dominant individuals among habitat types (e.g., Davies 1992). Whatever settlement model applies to a species, the most dominant individuals should be found disproportionately often within the preferred habitat type.

3. Site fidelity.-Habitat selection theory predicts, and empirical evidence illustrates (e.g., Sergio and Newton 2003), that individuals claiming territories in a preferred habitat will have the greatest site fidelity and the lowest rates of emigration. Conversely, individuals in lesspreferred habitats will relocate to claim territories in the preferred habitat when they become available (e.g., Weldon and Haddad 2005). Habitats can be ranked in order of preference, where more preferred habitats should be occupied by individuals with higher site fidelity and lower emigration rates.

4. Temporal variance in population size.-There should be large year-to-year changes in animal numbers in sites perceived as poor-quality habitats, but only small changes in those perceived as high-quality habitats. Hence, population density in good sites should be "buffered" by population density variation in poor sites (Kluyver and Tinbergen 1953, Brown 1969). Hence, lesspreferred habitats will be occupied only during years or time periods when populations are high and individuals are forced to settle in habitats they perceive as poor quality; conversely, population densities in preferred habitat types should be relatively stable (O'Connor 1981, Gill et al. 2001). Researchers can rank the relative preference with the more preferred habitats having the least variance in use among years and the less preferred habitats having the greatest variance.

5. Choice experiments. - Cues that animals use for habitat choice, and their relative preference for different cue sets, can be determined using an experimental approach in a laboratory or seminatural setting (e.g., Roberts and Weigl 1984, Kriska et al. 1998). However, because individuals normally face multiple environmental constraints (e.g., competition from other individuals), laboratory settings may not create the full range of cue types and strengths an individual would experience in a natural setting (but see Brown 1988).

The first four methods of measuring preference are field based and, alone, may not unequivocally establish preference due to potential confounding factors. For example, early arrival may not be correlated with habitat preference if there are alternative habitat selection strategies in a population (for example differences among age classes or morphs). Moreover, changes in territory use from one year to the next could conceivably reflect changing physiological needs rather than preference. Still, several correlated lines of evidence for habitat preference can provide greater certainty that preference is being accurately assessed. Experimental (lab or field-based) approaches to measuring preference are suggested where they are feasible.

To better assess the strength of evidence provided by authors, we also looked at whether the experimental units were replicated and whether treatments were randomly assigned. We considered individual animals or their territories to be samples within each habitat type. Comparative or experimental studies in which there was only one study plot per habitat type were considered unreplicated. Among studies that met all three criteria, replicated studies were considered to provide "strong" evidence for the existence of an ecological trap while unreplicated studies were considered to provide "weak" evidence.

\section{Results And Discussion}

\section{Empirical evidence for the existence of ecological traps}

We found 45 peer-reviewed papers (Table 1) in which the authors claimed that their research constituted evidence of an ecological trap or in which other authors cited the paper as having demonstrated the existence of an ecological trap. Because many of the studies were not designed to test for the existence of an ecological trap, a failure to satisfy our three criteria for demonstrating the presence of an ecological trap does not necessarily reflect a lack of quality in the study. Of the papers we reviewed, $27(60 \%)$ were replicated, but only two included randomization (Horváth et al. 1998, Kriska et al. 1998). In a few instances, replication was impossible due to the nature of the experiment, but, overall, it is 
unclear why many researchers did not choose to replicate.

Criterion 1: Measuring preference.-The authors of only eight (18\%) of the 45 studies we reviewed provided at least one reasonable measure of preference. Three used the mean arrival date of migratory birds in different habitat types to rank habitats in terms of perceived quality (Székely 1992, Remeš 2003, Lloyd and Martin 2005). Four studies used experimental methods to account for the availability of resources and then showed that one resource was chosen preferentially over another when both resources were equally available (Chew 1980, Horváth et al. 1998, Kriska et al. 1998, Pöysä et al. 1999). Finally, Weldon and Haddad (2005) used the relative age-class distribution and site fidelity of territorial males to rank habitats in terms of perceived quality. Among studies that failed to meet the first criterion, the density of nests, density of breeding territories, or density of individuals was relied upon or inferred to be an appropriate index of preference in 18 $(40 \%)$ of the reviewed studies. In addition, a total of six (13\%) of the 45 studies that we considered relied upon use-availability models to infer habitat preference based on nonrandom use (Mundy 1983, Johnson and Temple 1986, Crabtree et al. 1989, Boal and Mannan 2000, Misenhelter and Rotenberry 2000, Kolbe and Janzen 2002).

Five studies employing artificial nest experiments were designed to test the ecological trap hypothesis or were cited as doing so (Yahner and Wright 1985, Angelstam 1986, Ratti and Reese 1988, Pasitschniak-Arts and Messier 1995, Carignan and Villard 2002). These studies were primarily designed to assess the potential reproductive outcome of nest placement through the estimation of predation rates on artificial bird nests. Even if the placement of artificial nests were a good estimate of the placement of natural nests, and even if predation rates upon these nests were similar to those of natural nests, there is no way of knowing which locations a hypothetical bird might have perceived as superior or inferior. In the absence of an individual, the adaptive value of a behavior cannot be evaluated because there can be no measure of individual preference. For this reason alone, an artificial nest experiment cannot demonstrate the existence of an ecological trap.

Criteron 2: Fitness of individuals varies by habitat.-In terms of fitness, only one study obtained estimates of both adult survival and reproductive success (Thomas et al. 1996). Most authors opted to estimate either survival only (six of 45 , or $13 \%$ ) or reproductive success only ( 27 of 45 , or $60 \%$ ). Six papers provided no estimates of survival or reproduction. It is unclear to what extent artificial nest experiments reflect actual nest survival rates (Paton 1994).

Criterion 3: The animal has equal or lower fitness in the preferred habitat.- Only five of the reviewed papers contained the data necessary to meet this criterion
(Horváth et al. 1998, Kriska et al. 1998, Remeš 2003, Lloyd and Martin 2005, Weldon and Haddad 2005).

In summary, according to the criteria that we propose, only five studies have yet established existence of an ecological trap. Evidence is considered "strong" in the three replicated studies (Horváth et al. 1998, Kriska et al. 1998, Weldon and Haddad 2005) and "weak" in the two unreplicated studies (Remeš 2003, Lloyd and Martin 2005).

The strongest support comes from two experimental studies of habitat selection in insects belonging to the order Odonata. Orientation to polarized sources of light (polarotaxis) is the most important mechanism that guides dragonflies and mayflies during in their search for a suitable habitat or site for oviposition (Kriska et al. 1998, Horváth and Zeil 1996). Kriska et al. (1998) used experimental methods in the field to show that some types of asphalt also polarize light horizontally and that because of the relatively homogenous distribution of the degree and direction of polarization reflected from asphalt roads, roads can actually be much more attractive to mayflies than the surface of a pond or stream. In this way, Kriska et al. (1998) demonstrate that some types of asphalt act as a supernormal stimulus for water-seeking mayflies in comparison with the light reflected from water. In this instance, natural habitat is not altered, but a novel element is introduced, and it happens to mimic a traditional cue for habitat choice. As a result, mayflies lay their eggs on an inappropriate substrate where they are unable to hatch successfully; therefore, complete mortality of the clutch results. There is little question that asphalt is an ecological trap for mayflies. Kriska et al. (1998) appear to document a severe trap of the type described in scenario B-a supernormal cue has emerged from asphalt blacktop, which is an otherwise inappropriate, low-quality habitat.

Similarly, dragonflies (Anisoptera) and damselflies (Zygoptera) are highly attracted to the horizontally polarized light given off by crude oil slicks such as the lakes of oil that resulted from the destruction of oil pipelines during the Gulf War (Horváth and Zeil 1996). Dragonflies are preferentially attracted to crude and waste oil even when suitable sources of water are available nearby. Once insects land on the surface of the oil they are caught and eventually die (Horváth et al. 1998). Thus, waste oil slicks also act as supernormal stimuli for habitat selection behavior in water-seeking insects and appear to fit our description of a severe trap of the type described in scenario B.

Weldon and Haddad (2005) provide strong evidence that artificial forest edges can act as ecological traps for Indigo Buntings (Passerina cyanea). Buntings are highly attracted forest edges and have historically relied upon natural disturbance to create suitable early-successional habitat that was frequently disturbed and supported relatively low predator populations (Suarez et al. 1997). Weldon and Haddad (2005) show that experimentally created habitat patches with greater amounts of forest 
TABLE 1. A summary of our evaluation of the presence of each of three criteria (see Introduction: A conceptual model of an ecological trap) needed to demonstrate the existence of an ecological trap for each of 45 papers that we reviewed.

Angelstam (1986). Predation on one type of artificial bird nest is higher in clear-cuts than in other forest habitats.

Basore et al. (1986). Several bird species are more likely to nest in untilled than tilled cropland, despite below replacement-level reproduction in untilled habitat.

Best (1986). Many species of birds are attracted to settle and breed in tilled fields where their nests are often destroyed by tilling and planting activities.

Black et al. (1991). Young geese are excluded by older geese from native habitat. Poor food supply in agricultural habitat may impact survival during overwater migration.

Boal (1997), Boal and Mannan (2000). Urban nesting Cooper's Hawks exhibit higher breeding densities but lower reproductive success than exurban pairs.

Bollinger et al. (1990). Bobolink commonly nest in hayfields but few nests survive haycropping.

Carignan and Villard (2002). Predation rates on artificial nests in conifer plantations are higher than predation rates in native forest during some years.

Chasko and Gates (1982). The abundance of bird nests is higher in edge habitat near power lines than in forest interior despite a lower probability of fledging in that habitat.

Crabtree et al. (1989). Gadwall nest density is highest in locations where skunks forage most and nest predation is highest.

Dwernychuk and Boag (1972). Ducks nesting in association with island-nesting gulls experienced high hatching success, but heavy fledgling mortality.

Eadie et al. (1998), Semel and Sherman (2001). Brood parasitic Wood Ducks locate and parasitize artificial nest boxes most readily, but heavy parasitism causes nest failure.

Easton and Martin (1998). Nesting success of open-cup nesting birds is lower in herbicide-treated forest patches than in thinned or unthinned forest.

Ferreras and MacDonald (1999). Breeding success of Coot and Moorhen was lowest where an exotic predator is found.

Flaspohler et al. $(2001 a, b)$. Songbirds nest at higher densities near artificial forest edges than in interior forest, but experience greater predation rates near edges.

Galbraith (1988). Lapwings nest in agricultural fields and grazed habitats, but nests in arable fields are more likely to be destroyed by plowing.

Ganter and Cooke (1998). Rapid population growth of Snow Geese degrades habitat and young birds fail to recruit into the safer core areas of the colony due to poor food availability.

Gates and Gysel (1978). Nest and breeding bird density are greater near human-created forest edge where nest predation rates are highest.

Johnson and Temple (1986). Grassland breeding birds experience their greatest nest productivity farthest from forest edge where they are least abundant

Kershner and Bollinger (1996). Grassland birds breed in high densities at airports where nest failure is frequently caused by mowing.

Kolbe and Janzen (2002). Snapping turtle nest sites near residential structures are colder than normal, drastically biasing the offspring sex ratio toward females.

Loery et al. (1997). Chickadee survival rates are lower in years immediately following establishment of Tufted Titmouse.

Misenhelter and Rotenberry (2000). Sage Sparrows experience greater predation rates at nest sites with the most common vegetative characteristics.

Mundy (1983). Young vultures perching on power lines are often electrocuted, presumably because they are clumsier fliers.

Packard et al. (1989). Manatees congregate near artificial thermal refuges during severe winters, but may experience mortality when heated effluent is turned off.

Pasitschniak-Arts and Messier (1995). Artificial waterfowl nests experience a higher predation rate near habitat edge.

Pidgeon et al. (2003). Black-throated Sparrows experience lowest nest success in mesquite-dominated habitat where their abundance is highest.

Purcell and Verner (1998). California Towhee breed at higher density in ungrazed habitat, but experience greater productivity in grazed habitat.

Ratti and Reese (1988). Predation rates on artificial nests do not differ as a function of distance from forest-field edge.

Reed et al. (1985). Fledgling seabirds are attracted to bright artificial lights with which they often collide and die.

Ries and Fagan (2003). Predation on mantid egg cases is highest at habitat edges where egg cases are found at highest density.

\begin{tabular}{|c|c|}
\hline Preference index & $\begin{array}{c}\text { Reasonable } \\
\text { preference } \\
\text { measure? }\end{array}$ \\
\hline none & no \\
\hline density (nest) & no \\
\hline none & no \\
\hline none & no \\
\hline nonrandom use & no \\
\hline density (territory) & no \\
\hline none & no \\
\hline density (nest) & no \\
\hline nonrandom use & no \\
\hline none & no \\
\hline none & no \\
\hline density (territory) & no \\
\hline density (individual) & no \\
\hline density (nest) & no \\
\hline density (territory) & no \\
\hline none & no \\
\hline density (nest) & no \\
\hline nonrandom use & no \\
\hline density (individual) & no \\
\hline nonrandom use & no \\
\hline none & no \\
\hline nonrandom use & no \\
\hline nonrandom use & no \\
\hline density (individual) & no \\
\hline none & no \\
\hline density (nest) & no \\
\hline density (territory) & no \\
\hline none & no \\
\hline none & no \\
\hline density (egg case) & no \\
\hline
\end{tabular}


TABLe 1. Extended

\begin{tabular}{|c|c|c|}
\hline \multirow{2}{*}{$\begin{array}{c}\text { Criterion } 2 \\
\text { Habitat-specific } \\
\text { reproduction } \\
\text { or survival } \\
\text { estimated? }\end{array}$} & \multicolumn{2}{|c|}{ Criterion 3} \\
\hline & $\begin{array}{c}\text { Lower quality } \\
\text { habitat } \\
\text { preferred? }\end{array}$ & $\begin{array}{l}\text { Mechanism } \\
\text { type }\end{array}$ \\
\hline no & NA & NA \\
\hline yes & NA & NA \\
\hline no & $\mathrm{NA}$ & NA \\
\hline no & NA & NA \\
\hline yes & $\mathrm{NA}$ & NA \\
\hline yes & $\mathrm{NA}$ & NA \\
\hline no & NA & $\mathrm{NA}$ \\
\hline yes & NA & NA \\
\hline yes & NA & NA \\
\hline yes & NA & NA \\
\hline yes & $\mathrm{NA}$ & NA \\
\hline yes & NA & NA \\
\hline yes & $\mathrm{NA}$ & NA \\
\hline yes & $\mathrm{NA}$ & NA \\
\hline no & NA & $\mathrm{NA}$ \\
\hline yes & NA & NA \\
\hline yes & $\mathrm{NA}$ & NA \\
\hline yes & NA & NA \\
\hline yes & $\mathrm{NA}$ & $\mathrm{NA}$ \\
\hline yes & NA & NA \\
\hline yes & NA & NA \\
\hline yes & NA & NA \\
\hline yes & $\mathrm{NA}$ & NA \\
\hline no & NA & NA \\
\hline no & $\mathrm{NA}$ & NA \\
\hline yes & $\mathrm{NA}$ & NA \\
\hline yes & NA & NA \\
\hline no & $\mathrm{NA}$ & NA \\
\hline yes & NA & NA \\
\hline yes & $\mathrm{NA}$ & NA \\
\hline
\end{tabular}

edge attracted older territorial males that exhibit greater interannual site fidelity compared to patches with less forest edge. In addition, birds that nested closer to edges and in patches with more edge had lower annual reproductive success, presumably because anthropogenic edges are highly attractive to nest predators. Highly edgy patches of the convoluted shape created to attract buntings in this experiment are probably an evolutionary novelty and appear to act as a supernormal habitat selection cue. Weldon and Haddad (2005) appear to document a severe trap of the type described in scenario D-experimental cutting has produced a supernormal cue that simultaneously attracts buntings and their nest predators.

The remaining two studies were neither replicated nor randomized in design and, therefore, must be considered in that light. Nonetheless, Lloyd and Martin (2005) demonstrated that the Chestnut-collared Longspur (Calcarius ornatus) settled in patches of native and exotic habitat, but reproductive success was lower in monocultures of a nonnative plant due to elevated rates of nest predation. In addition, nestlings in the exotic habitat gained mass at a slower rate, took longer to fledge, and left the nest at a lower mass than nestlings in the native habitat, suggesting food limitation as a mechanism contributing to poor reproductive success in this habitat type. Because there was no significant difference in the mean arrival date of male longspurs or in the laying date of females settling in native and exotic habitats, it appears that longspurs regard both habitat types as equally attractive, which would make this an example of an "equal-preference" trap. Patches of exotic habitat appear to be ecological traps that may function as population sinks due to low annual reproductive success (Lloyd and Martin 2005). The introduction of a nonnative plant may or may not have caused a change in the cue set, but the overall attractiveness ended up the same as that in the native habitat while success there was less, so this case would fit under the mechanism described in scenario $\mathrm{C}$.

Finally, Remeš (2003) found that arriving blackcaps (Sylvia atricapilla) settled first in (preferred) a plantation of exotic black locust (Robinia pseudoacacia) relative to natural floodplain forest, but suffered lower nesting success there due to predation. The settlement cues used by individuals are unclear but are probably the earlier leafing of shrubs and/or food supply. This would represent the type of severe trap depicted in scenario $B$ because a novel, super attractive habitat has been created.

While there are currently an insufficient number of empirical studies available to determine which mechanism is more likely to trigger and ecological trap, it is interesting to note that the four studies we cite as the clearest examples of ecological traps illustrate the operation of all three of the possible mechanisms: two of type B (change in cue, but not ultimate factors; Horváth et al. 1998, Kriska et al. 1998), one of type C 


\begin{tabular}{lcc} 
& \multicolumn{2}{c}{ Criterion 1 } \\
\cline { 2 - 3 } Journal article and relevant study summary & Preference index & $\begin{array}{c}\text { Reasonable } \\
\text { preference } \\
\text { measure? }\end{array}$ \\
\hline Best (1983). Vesper Sparrow nest densities were highest closer & density (territory) & no
\end{tabular}

Rodenhouse and Best (1983). Vesper Sparrow nest densities were highest closer to agricultural fencerows where nest predation rates were highest. Fencerows may be predator corridors.

Schmidt and Whelan (1999). American Robin nests placed in two exotic plants experience higher predation rates than nests built in comparable native shrubs.

Shane (1984). Manatees are attracted to thermal effluent from power plants during winter but the unreliability of thermal effluent release may reduce survivorship.

Stallman and Best (1996). Breeding bird and nest abundance was relatively higher in an experimental agricultural treatment relative to other field types, but nest success was lower.

Thomas et al. (1996). Butterflies are attracted to breed in on a novel host plant in a harvested forest, but an early frost kills host plants after oviposition only in this habitat type.

Woodward et al. (2001). Some species of shrubland birds experience greater nest predation rates near habitat edges, but nest density is independent of distance from edge.

Yahner and Wright (1985). Predation of Ruffed Grouse nests in clear-cut forest is not related to distance from forest edge.

Chew (1980). Butterfly larvae readily orient to and feed upon exotic, but poisonous, plant species in laboratory choice tests.

Pöysä et al. (1999). Goldeneye females prefer nest sites located closer to forest edge, nearer shore, but suffer no detectable negative fitness consequences.

Székely (1992). Kentish Plovers experience low reproductive success in an artificial habitat type rich with food.

Horváth et al. (1988). Dragonflies are preferentially attracted to crude oil spills over water bodies. Landing on oil results in mortality.

Kriska et al. (1998). Mayflies are attracted to lay their eggs upon asphalt because it reflects polarized light at a supernormal intensity.

Lloyd and Martin (2005). Longspur show an equal preference for native- and exotic-dominated habitat, but experience lower nesting success and nestling growth rates in exotic habitat.

Remeš (2003). Blackcaps prefer a plantation of exotic black locust over natural floodplain forest, but suffer lower nesting success there due to nest predation.

Weldon and Haddad (2005). Indigo Buntings prefer habitat with greater amounts of artificial forest edge, but reproductive success is inversely correlated with the amount of habitat edge.

$\begin{array}{ll}\text { none } & \text { no } \\ \text { density (individuals) } & \text { no } \\ \text { density (nest) } & \text { no }\end{array}$

density (individual) no

density (nest) no

none no

choice experiment yes

choice experiment yes

arrival date yes

choice experiment yes

choice experiment yes

arrival date yes

arrival date yes

age class distribution/ yes site fidelity

Notes: Where the existence of a trap is supported by evidence, the possible mechanisms that could have triggered the trap are indicated. Studies are listed hierarchically by the criteria they satisfy, then alphabetically by author. A brief summary of the relevant conclusions of each study is given.

(change in ultimate factors, but not cues; Lloyd and Martin 2005), one of type D (change in both cues and ultimate factors; Weldon and Haddad 2005) and one of either type B or D (Remeš 2003). In addition, there is evidence for the existence of both equal preference (Lloyd and Martin 2005) and severe (Horváth et al. 1998, Kriska et al. 1999, Remeš 2003, Weldon and Haddad 2005) traps.

Even if a study demonstrates a negative relationship between a fitness component and an estimate of habitat preference, some caution is required before one can infer that the existence of a trap will result in a long-term population decline. In particular, a behavioral strategy that reduces survival or reproduction in the short term is not necessarily maladaptive if it enhances longer-term reproductive success. For example, characteristics of successful nest sites can vary over time and space (van
Riper 1984), and nest-site selection may reflect long-term optima that are neutral or maladaptive in the short term (Clark and Shutler 1999). In this way, temporal and spatial variation in selection could invalidate presumed differences between high- and low-quality habitats. Theoretically, the entire life cycle of an organism must be taken into account because a novel environment could have compensating effects on the survival and reproductive output of different life stages. At the very least, we can and should demonstrate that at least one aspect of, or one time period within, the life cycle of an organism has become compromised because of the existence of an ecological trap.

Why is there such a paucity of empirical evidence for the existence of ecological traps? One possibility is that ecological traps are quite rare. Alternatively, researchers may simply fail to detect them. Detecting an ecological 
TABle 1. Continued, extended.

\begin{tabular}{|c|c|c|}
\hline \multirow{3}{*}{$\begin{array}{l}\text { Criterion } 2 \\
\text { Habitat-specific } \\
\text { reproduction } \\
\text { or survival } \\
\text { estimated? }\end{array}$} & \multirow{2}{*}{\multicolumn{2}{|c|}{ Criterion 3}} \\
\hline & & \\
\hline & $\begin{array}{c}\text { Lower quality } \\
\text { habitat } \\
\text { preferred? }\end{array}$ & $\begin{array}{l}\text { Mechanism } \\
\text { type }\end{array}$ \\
\hline yes & NA & NA \\
\hline yes & NA & NA \\
\hline no & NA & NA \\
\hline yes & NA & NA \\
\hline yes & NA & NA \\
\hline yes & NA & NA \\
\hline no & NA & NA \\
\hline no & $\mathrm{NA}$ & NA \\
\hline yes & no & NA \\
\hline yes & no & NA \\
\hline yes & yes & B \\
\hline yes & yes & B \\
\hline yes & yes & $\mathrm{C}$ \\
\hline yes & yes & $\mathrm{B}$ or $\mathrm{D}$ \\
\hline yes & yes & $\mathrm{D}$ \\
\hline
\end{tabular}

trap requires a great deal of data, especially if a study is well replicated. Not only do researchers have to estimate habitat-specific survival and/or reproductive success among habitat types and replicate experimental plots, but they must obtain concurrent estimates of habitat preference. The rarity of studies adequately measuring preference should be highlighted because it probably reflects the inherent difficulty of demonstrating individual habitat preference. Nevertheless, demonstrating habitat preference is an important component of studies designed to detect the existence of ecological traps.

\section{Conclusion}

Results from this review and synthesis suggest that we have not been careful enough to correctly identify ecological traps on a case-by-case basis. In general, the literature on ecological and evolutionary traps has been dominated by demographic approaches that seek to understand the factors that shape population-level evolutionary responses to traps. However, progress in understanding the mechanisms by which traps are triggered and in identifying factors that predispose animals to responding to deceptive stimuli will need to embrace a behavioral approach that considers the conditions under which habitat selection behavior evolved, variation in habitat selection behavior among individuals in a population, and the importance of learning.

A close examination of the mechanisms that create traps associated with specific kinds of habitat alteration (or even with specific kinds of restoration activity) will be an important step toward mitigating the negative effects of traps. Further research into this interesting phenomenon should lead us toward an ability to identify, correct, and potentially even prevent the occurrence of traps in the future where they threaten the persistence of native species. If a more holistic and synthetic theory of the ecological trap is to be developed it will be essential to have a library of empirical studies illustrating not only the breadth of impacts that cause ecological traps and the range of species that are susceptible to them, but also a depth of understanding that examines the mechanisms that can trigger maladaptive behavior in general.

\section{ACKNOWLEDGMENTS}

This paper received the benefit of review comments from numerous individuals, including Doug Emlen, Robert Fletcher, Erick Greene, and Joseph Fontaine. We are especially grateful to Martin Schlaepfer and another anonymous reviewer; the depth of questions and comments posed by reviewers improved both the manuscript and our own understanding of the subject of ecological traps. The ideas herein were stimulated by our research on ecological traps, supported by an Americorps Conservation Scholarship and the Rocky Mountain Research Station, Forest Service, U.S. Department of Agriculture.

\section{Literature Cited}

Angelstam, P. 1986. Predation on ground-nesting birds' nests in relation to predator densities and habitat edge. Oikos 47:365373.

Basore, N. S., L. B. Best, and J. B. Wooley, Jr. 1986. Birds nesting in Iowa no-tillage and tilled cropland. Journal of Wildlife Management 50:19-28.

Battin, J. 2004. When good animals love bad habitats: ecological traps and the conservation of animal populations. Conservation Biology 18:1482-1491.

Best, L. B. 1986. Conservation tillage: ecological traps for nesting birds? Wildlife Society Bulletin 14:308-317.

Black, J. M., C. Deerenberg, and M. Owen. 1991. Foraging behaviour and site selection of barnacle geese Branta leucopsis in a traditional and newly colonized spring staging habitat. Ardea 79:349-358.

Boal, C. W. 1997. An urban environment as an ecological trap for Cooper's Hawks. Dissertation, University of Arizona, Tucson, Arizona, USA.

Boal, C. W., and R. W. Mannan. 2000. Cooper's Hawks in urban and exurban areas: a reply. Journal of Wildlife Management 64:601-604.

Bollinger, E. K., P. B. Bollinger, and T. A. Gavin. 1990. Effects of hay-cropping eastern populations of the bobolink. Wildlife Society Bulletin 18:142-150.

Brown, J. L. 1969. The buffer effect and productivity in tit populations. American Naturalist 103:347-354 
Brown, J. S. 1988. Patch use as an indicator of habitat preference, predation risk, and competition. Behavioral Ecology and Sociobiology 22:37-47.

Carignan, V., and M. Villard. 2002. Effects of variations in micro-mammal abundance on artificial nest predation in conifer plantations and adjoining deciduous forests. Forest Ecology and Management 157:255-265.

Chasko, G. C., and J. E. Gates. 1982. Avian habitat suitability along a transmission-line corridor in an oak-hickory forest region. Wildlife Monographs 82:1-41.

Chew, F. 1980. Food plant preferences of Pieris caterpillars. Oecologia 46:347-353.

Clark, R. G., and D. Shutler. 1999. Avian habitat selection: pattern from process in nest-site use by ducks? Ecology 80: 272-287.

Crabtree, R., L. Broome, and M. Wolfe. 1989. Effects of habitat characterization on gadwall nest predation and nestsite selection. Journal of Wildlife Management 53:129-137.

Davies, N. B. 1992. Dunnock behaviour and social organization. Cambridge University Press, Cambridge, UK.

Dwernychuk, L. W., and D. A. Boag. 1972. Ducks nesting in association with gulls - an ecological trap? Canadian Journal of Zoology 50:559-563.

Eadie, J. M., P. M. Sherman, and B. Semel. 1998. Conspecific brood parasitism, population dynamics, and the conservation of cavity nesting birds. Pages 306-340 in T. M. Caro, editor. Behavioral ecological and conservation biology. Oxford University Press, Oxford, UK.

Easton, W. E., and K. Martin. 1998. The effect of vegetation management on breeding bird communities in British Columbia. Ecological Applications 8:1092-1103.

Ferreras, P., and D.W. Macdonald. 1999. The impact of the American mink Mustela vison on water birds in the upper Thames. Journal of Applied Ecology 36:701-708.

Flaspohler, D. J., S. A. Temple, and R. N. Rosenfeld. $2001 a$. Effects of forest edges on ovenbird demography in a managed forest landscape. Conservation Biology 15:173183.

Flaspohler, D. J., S. A. Temple, and R. N. Rosenfield. $2001 b$. Species-specific edge effects on nest success and breeding bird density in a forested landscape. Ecological Applications 11: 32-46.

Fretwell, S. D., and H. J. Lucas. 1970. On territorial behavior and other factors influencing habitat distribution in birds. Acta Biotheoretica 19:16-36.

Galbraith, H. 1989. Arrival and habitat use by lapwings Vanellus vanellus in the early breeding season. Ibis 131:377388.

Ganter, B., and F. Cooke. 1998. Colonial nesters in a deteriorating habitat: site fidelity and colony dynamics of Lesser Snow Geese. Auk 115:642-652.

Gates, J. E., and L. W. Gysel. 1978. Avian nest dispersion and fledging success in field-forest ecotones. Ecology 59:871-883.

Gill, J., K. Norris, P. Potts, T. Gunnarsson, P. Atkinson, and W. J. Sutherland. 2001. The buffer effect and large-scale population regulation in migratory birds. Nature 142:436438

Horváth, G., B. Bernáth, and G. Molinár. 1998. Dragonflies find crude oil visually more attractive than water: multiplechoice experiments on dragonfly polarotaxis. Naturwissenschaften 85:292-297.

Horváth, G., and J. Zeil. 1996. Kuwait oil lakes as insect traps. Nature 379:303-304.

Hutto, R. 1985. Habitat selection by nonbreeding migratory land birds. Pages 455-476 in M. Cody, editor. Habitat selection in birds. Academic Press, London, UK.

Johnson, D. H. 1980. The comparison of usage and availability measurements for evaluating resource preference. Ecology 61:65-71.

Johnson, R. G., and S. A. Temple. 1986. Assessing habitat quality for birds nesting in fragmented tallgrass prairies.
Pages 245-249 in J. Verner, M. L. Morrison, and C. J. Ralph, editors. Wildlife 2000: modeling habitat relationships of terrestrial vertebrates. University of Wisconsin press, Madison, Wisconsin, USA.

Kershner, E. L., and E. K. Bollinger. 1996. Reproductive success of grassland birds at east-central Illinois airports. American Midland Naturalist 136:358-366.

Kluyver, H. N., and L. Tinbergen. 1953. Territory and regulation of density in titmice. Archives Néerlandaises de Zoologie 10:265-289.

Kolbe, J. J., and F. J. Janzen. 2002. Impact of nest-site selection on nest success and nest temperature in natural and disturbed habitats. Ecology 83:269-281.

Krebs, J. R. 1971. Territory and breeding density in the Great Tit, Parus major. Ecology 52:2-22.

Kriska, G., G. Horvath, and S. Andrikovics. 1998. Why do mayflies lay their eggs en masse on dry asphalt roads? Waterimitating polarized light reflected from asphalt attracts Ephemeroptera. Journal of Experimental Biology 201:22732286.

Levins, R. 1968. Evolution in changing environments. Princeton University Press, Princeton, New Jersey, USA.

Lloyd, J. D., and T. E. Martin. 2005. Reproductive success of Chestnut-collared Longspurs in native and exotic grassland. Condor 107:363-374.

Loery, G., J. D. Nichols, and J. E. Hines. 1997. Capturerecapture analysis of a wintering Black-capped Chickadee population in Connecticut, 1958-1993. Auk 114:431-442.

Misenhelter, M. D., and J. Rotenberry. 2000. Choices and consequences of habitat occupancy and nest site selection in Sage Sparrows. Ecology 81:2892-2901.

Mundy, P. J. 1983. The conservation of the Cape Griffon Vulture of Southern Africa. Pages 57-74 in S. R. Wilbur and J. A. Jackson, editors. Vulture biology and management. University of California Press, Berkeley, California, USA.

O'Connor, R. J. 1981. Habitat correlates of bird distribution in British census plots. Studies in Avian Biology 6:533-537.

Packard, J. M., R. K. Frohlich, J. E. Reynolds, III, and J. R. Wilcox. 1989. Manatee response to interruption of a thermal effluent. Journal of Wildlife Management 53:692-700.

Pasitschniak-Arts, M., and F. Messier. 1995. Risk of predation on waterfowl nests in the Canadian prairies: effects of habitat edges and agricultural practices. Oikos 73:347-355.

Paton, P. W. 1994. The effect of edge on avian nest success: how strong is the evidence? Conservation Biology 8:17-26.

Pidgeon, A. M., V. C. Radeloff, and N. E. Mathews. 2003. Landscape-scale patterns of Black-throated Sparrow ( $\mathrm{Am}$ phispiza bilineata) abundance and nest success. Ecological Applications 13:530-542.

Pöysä, H., M. Milonoff, V. Ruusila, and J. Virtanen. 1999. Nest-site selection in relation to habitat edge: experiments in the Common Goldeneye. Journal of Avian Biology 30:79-84.

Purcell, K. L., and J. Verner. 1998. Density and reproductive success of California Towhee. Conservation Biology 12:442450.

Railsback, S. F., H. B. Stauffer, and B. C. Harvey. 2003. What can habitat preference models tell us? Tests using a virtual trout population. Ecological Applications 13:1580-1594.

Ratti, J. T., and K. P. Reese. 1988. Preliminary test of the ecological trap hypothesis. Journal of Wildlife Management 52:484-491.

Reed, J. R., J. L. Sincock, and J. P. Hailman. 1985. Light attraction in endangered procellariiform birds: reduction by shielding upward radiation. Auk 102:377-383.

Remeš, V. 2003. Effects of exotic habitat on nesting success, territory density and settlement patterns in the Blackcap (Sylvia atricapilla). Conservation Biology 17:1127-1133.

Ries, L., and W. F. Fagan. 2003. Habitat edges as a potential ecological trap for an insect predator. Ecological Entomology 28:567-572. 
Roberts, E. P., and P. D. Weigl. 1984. Habitat preference in the Dark-eyed Junco (Junco hyemalis): the role of photoperiod and dominance. Animal Behaviour 32:709-714.

Rodenhouse, N. L., and L. B. Best. 1983. Breeding ecology of Vesper Sparrow in corn and soybean fields. American Midland Naturalist 110:265-275.

Schlaepfer, M. A., M. C. Runge, and P. W. Sherman. 2002. Ecological and evolutionary traps. Trends in Ecology and Evolution 17:474-480.

Schmidt, K. A., and C. J. Whelan. 1999. Effects of exotic Lonicera and Rhamnus on songbird nest predation. Conservation Biology 13:1502-1506

Semel, B., and P. W. Sherman. 2001. Intraspecific parasitism and nest-site competition in wood ducks. Animal Behavior 61:787-803.

Sergio, F., and I. Newton. 2003. Occupancy as a measure of territory quality. Journal of Animal Ecology 72:857-865.

Shane, S. H. 1984. Manatee use of power plant effluents in Brevard County, Florida. Florida Scientist 47:180-187.

Sherman, P. W. 1988. The levels of analysis. Animal Behaviour 36:616-618

Sherry, T. W., and R. T. Holmes. 1988, Habitat selection by breeding American Redstarts in response to a dominant competitor, the Least Flycatcher. Auk 96:350-364.

Stallman, H. R., and L. B. Best. 1996. Bird use of an experimental strip intercropping system in northeast Iowa. Journal of Wildlife Management 60:354-362.

Suarez, A. V., K. S. Pfennig, and S. K. Robinson. 1997. Nesting success of a disturbance-dependent songbird on different kinds of edges. Conservation Biology 11:928-935.
Székely, T. 1992. Reproduction of Kentish Plover (Charadrius alexandrinus) in grassland and fish ponds: the habitat malassessment hypothesis. Aguila 99:59-68.

Thomas, C. D., M. C. Singer, and D. A. Boughton. 1996. Catastrophic extinction of population sources in a butterfly metapopulation. American Naturalist 148:957-975.

Tinbergen N. 1963. On the aims and methods of ethology. Zeitschrift fur Tierpsychol 20:410-463.

Van Horne, B. 1983. Density as misleading indicator of habitat quality. Journal of Wildlife Management 47:893-901.

van Riper, C., III. 1984. The influence of nectar resources on nesting success and movement patterns of the Common Amakihi. Auk 101:38-46.

Weldon, A. J., and N. M. Haddad. 2005. The effects of patch shape on Indigo Buntings: evidence for an ecological trap. Ecology 86:1422-1431.

Witherington, B. E. 1997. The problem of photopollution for sea turtles and other nocturnal animals. Pages 303-328 in J. R. Clemmons and R. Bucholz, editors. Behavioral approaches to conservation in the wild. Cambridge University press, Cambridge, UK.

Woodward, A. A., A. D. Fink, and F. R. Thompson, III. 2001. Edge effects and ecological traps: effects on shrubland birds in Missouri. Journal of Wildlife Management. 65:668675.

Yahner, R. H., and A. L. Wright. 1985. Depredation on artificial ground nests: effects of edge and plot age. Journal of Wildlife Management 49:508-513. 